\title{
Zone electrophoresis of enteroviruses
}

\author{
BY A. POLSON AND D. DEEKS \\ The C.S.I.R. and U.C.T. Virus Research Unit, Medical School, Cape Town
}

(Received 24 November 1961)

INTRODUCTION

In earlier physico-chemical studies particle size was regarded as a property whereby one virus type could be differentiated from another. It was used by Elford (1938) to distinguish viruses of foot and mouth disease and vesicular stomatitis, which produce similar clinical manifestations. When more accurate methods for particle size determination were developed, it became clear that a virus could not be identified by particle size alone.

In searching for other physico-chemical properties for differentiating enteroviruses, a study was made of rates of migration in the electric field under standardized experimental conditions. The electrophoresis technique of Tiselius is applicable only if relatively large amounts of purified virus, sufficient to cause measurable light refraction effects, are available. Such quantities of pure virus can be obtained only in rare instances. A modification of Tiselius' technique in which migration of the infective particle was followed by a sampling technique, was used by Polson, Selzer \& van den Ende (1957) to establish the migration rate of the MEF 1 strain of Type 2 poliovirus, but this technique is cumbersome and may not reveal the existence of minor infective components with different mobilities. Zone electrophoresis (Z.E.) in a density gradient was applied in investigations of F.A. mouse encephalomyelitis virus by Cramer, Lerner \& Polson (1957) and of Type 1 poliovirus by Polson \& Cramer (1958). It was found that although these viruses have similar sedimentation constants and probably are of identical particle size, they differ in mobility in the electric field. This technique has been used in this study of enteroviruses.

\section{METHODS AND MATERIALS}

\section{Viruses}

The following enteroviruses were examined in this work: Coxsackie A, Types 1-19 and 22-24; Coxsackie B, Types 1-5; ECHO, Types 1-9 and 11-13; Poliomyelitis, Types 1-3.

The Coxsackie A and B viruses, the ECHO viruses and the Stockholm strain of Type 1 poliovirus were kindly supplied by Dr T. Johnsson of the State Bacteriological Laboratory, Stockholm; the Mahoney strain of Type 1 poliovirus by Dr N. Stanley of Melbourne; the MEF 1 strain of Type 2 and the Templeon strain of Type 3 poliovirus by Dr James Gear of the Poliomyelitis Research Foundation, Johannesburg. 


\section{Apparatus}

The zone electrophoresis (Z.E.) apparatus (Pl. 1, fig. 1) used in this work is a simplified modification of that designed by Svensson \& Valmet (1955) and described in detail by Polson \& Cramer (1958). The electrophoreses were carried out under standardized conditions of $\mathrm{pH}$, potential and concentration gradients, and ionic strength of the buffer. The extent of migration of the virus in the concentration gradient column was expressed in relation to the distance which two pigments, rabbit haemoglobin and phenol red, migrated in the column. The Z.E. experiments were terminated when the haemoglobin had migrated approximately $3 \mathrm{~cm}$. and the phenol red $15-16 \mathrm{~cm}$., that is after about 18 hours with a current of approximately $25 \mathrm{~mA}$. and a potential difference between the electrodes of $200 \mathrm{~V}$. The column was fractionated as described previously by Polson \& Cramer (1958).

\section{Buffers and solutions}

Borate buffer was used exclusively throughout this work and it had the following composition:

$$
\begin{aligned}
& 0.035 \mathrm{M} \mathrm{H}_{3} \mathrm{BO}_{3} \\
& 0.0175 \mathrm{NaOH} \\
& \hline 0.0075 \mathrm{NCl} \\
& 0.073 \mathrm{M} \mathrm{NaCl}, \mathrm{pH} 8.60
\end{aligned}
$$

Difco sucrose or refined household sugar was used for the concentration gradients. When the Z.E. apparatus was used for purification purposes, and solutions were required which were free of colloidal matter, the latter was separated from the sugar solution by dialysis.

\section{Borate-sugar interaction}

It is well known that borate ions react with sucrose to form a borate-sugar complex, and as a result the $\mathrm{pH}$ of the buffer is lowered. The $\mathrm{pH}$ may then be readjusted to the original figure by the addition of sodium hydroxide. In the present work it was found that when borate buffer of $\mathrm{pH} \mathbf{8 . 6}$ is used in the preparation of $40 \%$ sucrose the $\mathrm{pH}$ is lowered to approximately $\mathbf{7 \cdot 4}$. By the addition of about $7.5 \mathrm{ml}$. of $\mathrm{N} \mathrm{NaOH}$ to $300 \mathrm{ml}$. of the $40 \%$ sugar-buffer mixture which is used for the gradient, the $\mathrm{pH}$ was restored to the original 8.6. This apparent defect of the borate-buffer system has the advantage that the conductivity of the buffer in the gradient column is increased at a rate proportional to the sugar content. As a result the voltage gradient in the column becomes less steep when a potential difference is applied across the electrodes in their containing vessels.

\section{Sugar concentration gradient}

Concentration gradient curves were obtained from light refraction measurements on the fractions taken from the Z.E. column. An Abbe refractometer was found suitable for the purpose. 


\section{Potential gradient in the column}

The potential gradient down the sugar density gradient column was measured with the aid of a pair of freshly platinized electrodes. These were held in two finely drawn glass capillary tubes, and the potentiometric attachment of the Beckman pH meter was used as the potentiometer. The ends of the electrodes across which the potential differences were measured were $2 \mathrm{~mm}$. apart and the determinations were made at centimetre intervals by lowering the electrodes into the column. Such measurements were made before and after completion of a typical Z.E. experiment.

\section{Purification of viruses}

In order to minimize possible mechanical transport of the virus by tissue fragments, the amount of tissue protein and debris in the preparation to be subjected to Z.E. was reduced by partial purification prior to electrophoresis. The purification method adopted was dependent on the source of the virus.

Infected monkey kidney cell (M.K.) tissue culture fluid (generally 10-20 ml., but up to approximately $500 \mathrm{ml}$. for some purposes) or suckling mouse brain emulsions (approximately ten brains per experiment) were partially purified by three cycles of ultracentrifugation in the model L Spinco: 12,000 r.p.m. for $10 \mathrm{~min}$. to remove tissue debris; 30,000 r.p.m. for $90 \mathrm{~min}$. to concentrate the virus in a pellet which was then redispersed in $2.2 \mathrm{ml}$. $35 \%$ sugar-buffer solution; and 8000 r.p.m. for $10 \mathrm{~min}$. to remove coagulated matter. This material, to which had been added the two reference pigments, was introduced into the column.

Infective carcasses (the numbers used varying from six to fifty, depending on the purpose of the experiment) were ground up in $10 \%$ rabbit serum saline and the emulsion centrifuged at 10,000 r.p.m. for $10 \mathrm{~min}$. to remove the coarse tissue. The virus and large protein molecules were then spun down at 35,000 r.p.m. for $60 \mathrm{~min}$. and the pellets redispersed in approximately $1 \mathrm{ml}$. saline per carcass. This was shaken twice with an equal volume of chloroform (Polson \& Selzer, 1954; Polson \& Hampton, 1957) to remove proteins which had sedimented with the virus. The infectious agent was spun down and redispersed in $2.2 \mathrm{ml} .35 \%$ sugar-buffer solution (containing the reference pigments) and finally prepared for electrophoresis by a clarifying centrifugation run at 8000 r.p.m. for $10 \mathrm{~min}$.

\section{Examination of the Z.E. column by Tyndall light scattering}

The purification method adopted prior to Z.E. should ensure that the bulk of the soluble protein components originally present in the crude virus suspension are appreciably reduced. Tissue components and debris which have particle sizes close to that of the infectious agent are probably the only contaminants present at this stage. If these components comprise a considerable portion of the total material they are visible as zones of light scattering in the gradient column on illumination with a bright light.

A lamp was specially constructed for this purpose and consists of a vertical fluorescent tube encased in a metal cylinder in which a slit $1 \mathrm{~cm}$. wide extends down the entire length of the cylinder. The lamp is placed next to the electro- 
phoresis column after completion of the Z.E. run, and faint to moderate zones of light scattering are then recorded photographically on sensitive film (Ilford Process Film N 8.40, which gives high contrast, was used). Density regions in this photographic negative may be measured on a Weston photographic analyser and presented graphically. Regions of very low density which might otherwise have escaped observation may be recorded in this manner.

No recordable light scattering due to the virus zones was expected with the virus concentrations used in the present work. However, such regions of light dispersion were noticed when relatively high concentrations of virus were subjected to electrophoresis (Polson, Hampton \& Deeks, 1960; Regenmortel, 1960). If a photographic recording is compared with its corresponding electrophoresis infectivity diagram it may be established whether or not a virus suspension may be purified by zone electrophoresis under the standard conditions of the present experiments.

\section{Electron microscopy}

After the peak of virus activity has been located by infectivity tests, the fractions containing the maximum activity may be dialysed free of sugar and the virus sedimented from these by ultracentrifugation. The redispersed pellets may then be subjected to electron microscopy. Unfortunately the available quantities of virus (10-40 ml. tissue culture fluid) used in the present work were generally inadequate for electron microscopy. In a few cases in which the virus had been concentrated from $500 \mathrm{ml}$. infected tissue culture fluid it was possible to show the presence of the virus particles by electron microscopy in the Z.E. samples which showed the highest infectivity titres.

\section{Influence of the type of host cell on the electrophoretic mobility}

It was thought possible that the type of cell in which the virus is grown might influence the electrophoretic mobility of the virus. This possibility was investigated using representative viruses of each of the four groups of infective agents which could be grown in monkey kidney tissue culture cells and either in suckling mice or in suckling mouse brain. The following viruses were investigated from this point of view : Coxsackie A 9 grown in suckling mice and in monkey kidney (M.K.) cells, ECHO 9 cultivated in M.K. cells and Coxsackie A 23 in suckling mice (these two classifications refer to the same virus (Sickles, Mutterer \& Plager, 1959)); Coxsackie B1 grown in suckling mice and in M.K. cells; Coxsackie B3 grown in suckling mice and in M.K. cells; Coxsackie B 4 grown in suckling mice and in M.K. cells.

\section{Titration of the fractions from the Z.E. column}

The Z.E. fractions were, as a rule, titrated in the type of tissue from which the infective virus had been derived. Thus, polio and ECHO viruses which were obtained from infected monkey kidney cells were titrated in the same type of cells using, routinely, three tubes per tenfold dilution. The Coxsackie B viruses were similarly propagated and titrated except when the effect of the host cell was investigated, in which case suckling mice were also used in propagation and 
titration. Coxsackie A viruses which grow very readily in 1-2-day-old suckling mice were titrated in suckling mice using one litter of 6-8 per tenfold dilution. Tenfold dilutions were made in $5 \%$ rabbit serum saline. Each suckling received $0.02 \mathrm{ml}$. subcutaneously in the interscapular region.

\section{RESULTS}

\section{Concentration and voltage gradients}

Diagrams illustrating a typical sugar concentration gradient after completion of a Z.E. experiment and potential gradient curves obtained before and after a similar Z.E. run are presented in Text-fig. 1. The concentration gradients prepared by this

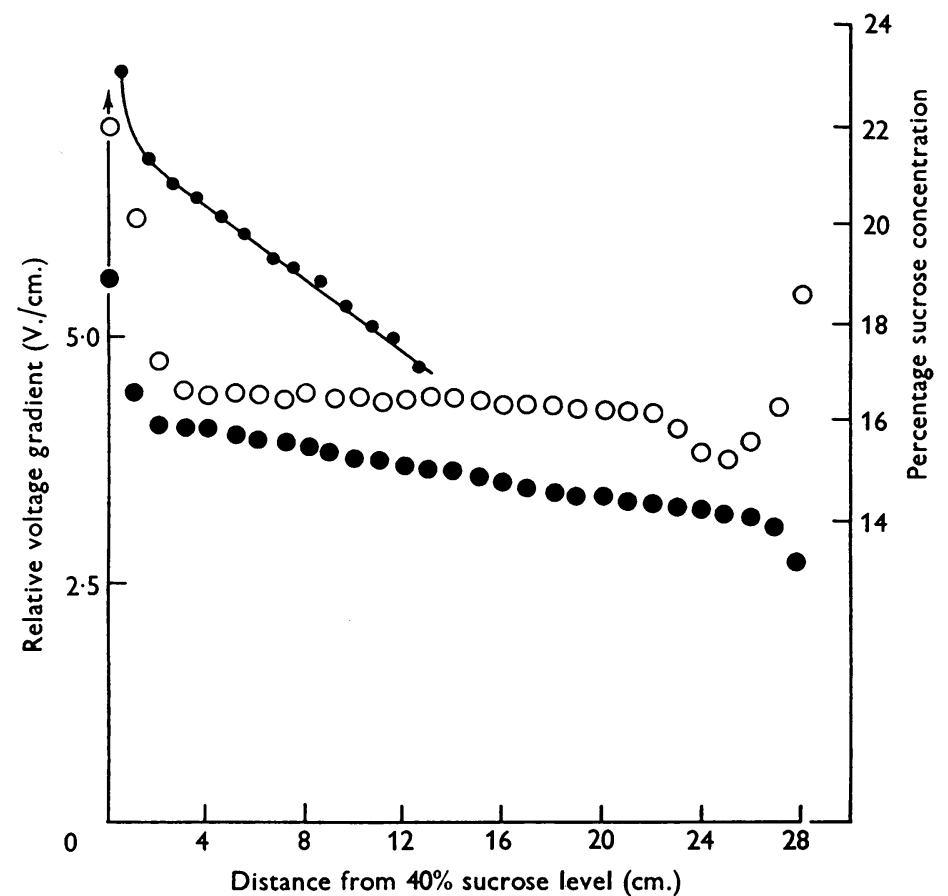

Text-fig. 1. Sugar concentration gradient (-), voltage gradient before Z.E. run $(\bullet)$ and voltage gradient after Z.E. run (O) plotted against distance in Z.E. column.

method should vary exponentially with distance along the column. The concentration curves are linear for all practical purposes in the range in which the observations are made. The figures presented (on the voltage gradient curves) are not absolute values as the shapes of the electrodes used for measuring the potential gradient are such that no accurate electrode constant could be calculated for them. However the curves illustrate that the potential gradient varies linearly with distance along the column and that it becomes less steep during the course of a Z.E. run. 


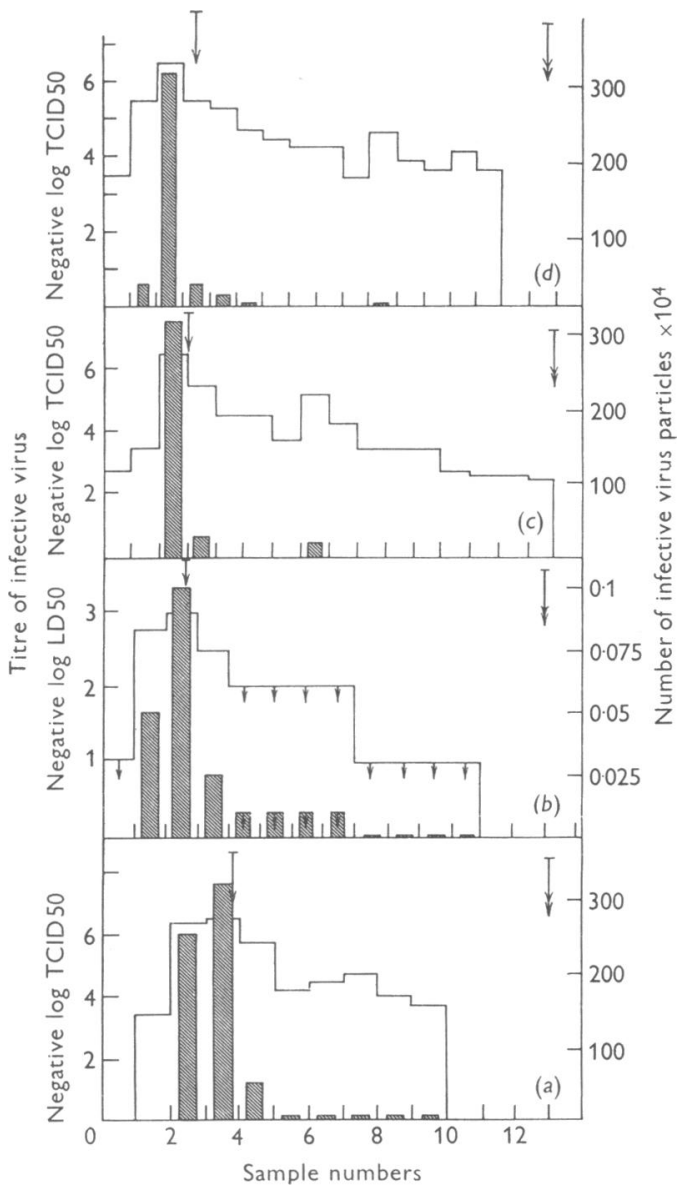

Fig. 2

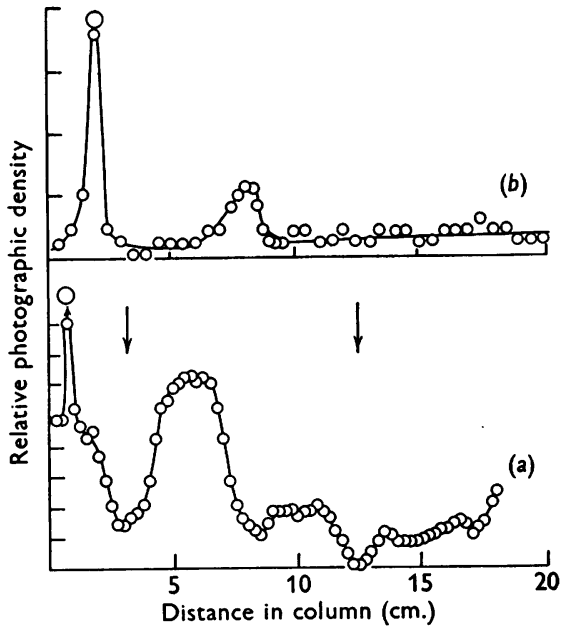

Fig. 3

Text-fig. 2. Zone electrophoresis diagrams of poliovirus. The long single and double arrows indicate the levels of the haemoglobin and phenol red, respectively. The short arrows indicate titres lower than what is indicated by the histograms. The unshaded histograms indicate the titres of the fractions expressed as negative log ID 50. In the shaded histograms these titres are expressed numerically. (The same system is used in all the following histograms.)

(a) Cincinnati strain of Type 1 poliovirus, done on tissue culture material. (b) Mahoney strain of Type 1 poliovirus, done on suckling mouse brain material titrated in young adult mice. (c) MEF 1 strain of Type 2 poliovirus, using tissue culture material. (d) Templeon strain of Type 3 poliovirus, using tissue culture material.

Text-fig. 3. (a) Light-scattering diagram obtained from photograph of Z.E. column after zone electrophoresis of Mahoney virus (suckling mouse brain material). The long arrows indicate the positions of the indicator substances, haemoglobin (left) and phenol red (right). ' $O$ ' indicates the starting position. The sharp peak at the origin in this and all the following light scattering diagrams is caused by a grease pencil mark made on the Z.E. column before photography, and is not significant. The peak of virus activity was found slightly to the left of the haemoglobin peak. (b) Light-scattering diagram obtained from photograph of Z.E. column contents after Z.E. of MEF 1 vaccine concentrate. The low peak is entirely due to the light scattering of the inactivated virus. 


\section{Zone electrophoresis}

The electrophoresis column is fractionated in the manner described previously (Polson \& Cramer, 1958) and infectivity titrations are done on the samples. The titres obtained are plotted against the distance from the original virus level at which the fraction was taken. Representative diagrams of the different groups of viruses are presented as well as diagrams of members which behave in a different manner, from those of the main biological group, as demonstrated by electrophoresis.

\section{Poliovirus}

Text-figs. $2(a)-(d)$ are Z.E. diagrams obtained with the three types of poliovirus. Several strains of Type 1 were investigated with very similar results. Two of these, namely Mahoney and Cincinnati are presented. The polioviruses in general show peaks of activity which have migration rates slightly lower than that of rabbit haemoglobin in the present buffer at $\mathrm{pH} 8 \cdot 6$. In addition to the main components there are also components of much lower peak titres which travelled faster than the main fractions.

A light scattering diagram obtained from a Z.E. experiment on crude Type 1 poliovirus (Mahoney strain) is shown in Text-fig. $3(a)$. No demonstrable light scattering could be expected from the virus particles in this experiment on account of the relatively low titre as they were present in too small numbers. The positions of the two reference substances, haemoglobin and phenol red, and the zone of maximum virus activity are indicated. It is obvious that a considerable degree of purification of the virus may be achieved by zone electrophoresis alone.

Text-fig. $3(b)$ is a light-scattering diagram obtained from a Z.E. experiment on purified Type 2 poliovirus inactivated by formaldehyde (Polson et al. 1960). The virus was obtained from $5 \mathrm{l}$. of infective tissue culture fluid.

\section{Coxsackie $A$ viruses}

Zone electrophoresis diagrams of this group of viruses are presented in Textfig. $4(a)-(d)$. These diagrams include a typical member of the group (A5) and members which depart from the general electrophoretic behaviour of the group. The viruses which behave differently are Coxsackie A 2, which has no mobility at pH 8.6; A 13, which gives a broad peak extending from just beyond the haemoglobin to midway between the two reference pigments; and A 14, which travels slightly faster than haemoglobin. The A 2 and A 13 results were confirmed, but only one run was done on A 14. The large majority of the Coxsackie A viruses travel at rates just short of that of rabbit haemoglobin and in this respect have a property in common with poliovirus.

A light-scattering diagram of a typical member of this group is shown in Textfig. 5. From the diagram and the results set out in Table 1 it is clear that the activity peak is also well separable from the bulk of the light-scattering material.

\section{Coxsackie $B$ viruses}

Coxsackie B 1 and B3 Z.E. diagrams appear in Text-fig. $6(a)$ and (b). The diagram of $B 1$ is typical of this group, but B 3 virus behaves differently from the 
rest in showing a main activity peak which travels slightly slower than haemoglobin and a second component which has a mobility similar to that of the rest of the $B$ group. In the case of Coxsackie B 1 virus the activity coincides with the bulk of the extraneous material, as is evident from the light-dispersion Z.E. diagram, Text-fig. 7, and a satisfactory degree of purification cannot thus be obtained by Z.E. alone. This probably applies to the rest of the B family except B 3, of which the slower-migrating component was isolated in a relatively pure state.

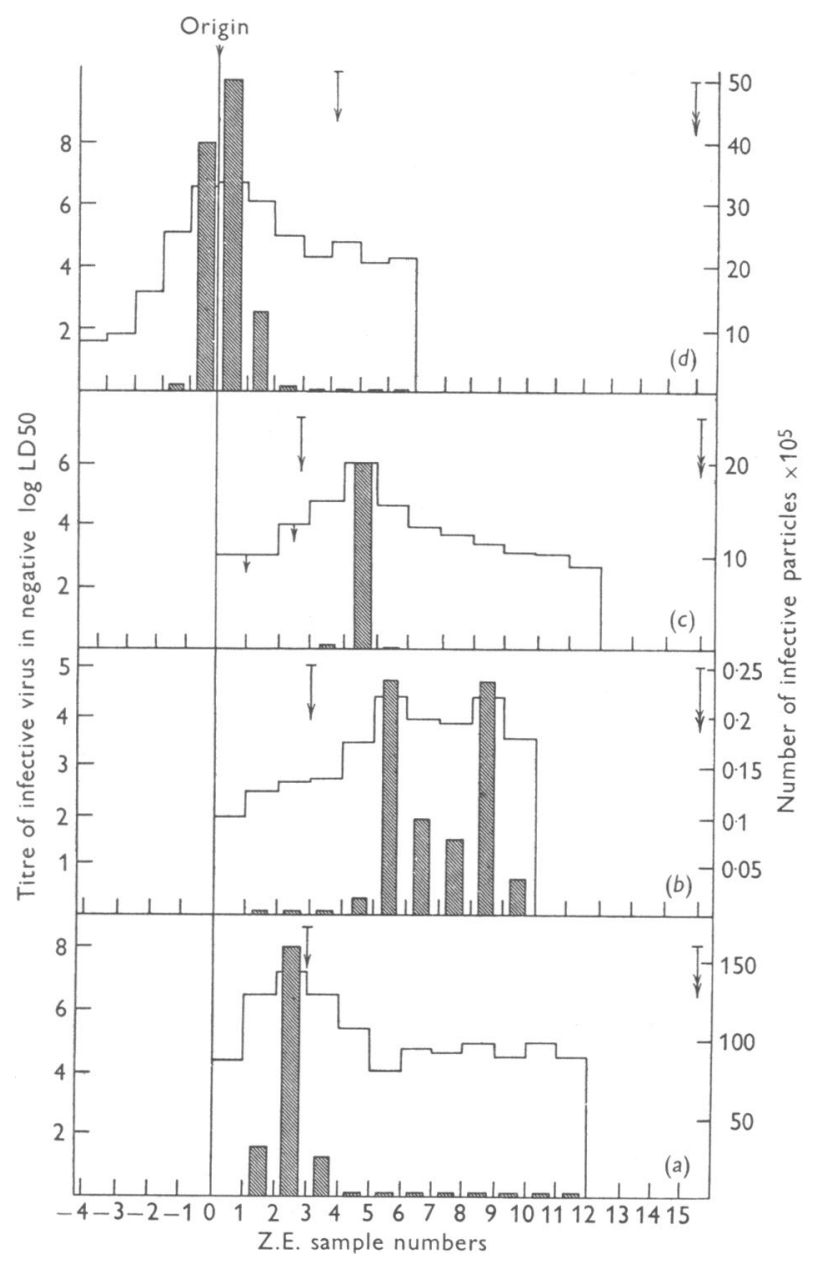

Text-fig. 4. (a) Zone electrophoresis histogram of Coxsackie A5 virus whose electrophoretic behaviour is typical of this family of viruses. $(b),(c)$ and $(d)$ Histograms of Coxsackie A 13, 14 and 2 respectively. These are electrophoretically atypical. Note that Coxsackie A 2 shows no mobility at this $\mathrm{pH}$. Suckling mouse material was used in all cases.

\section{ECHO viruses}

The electrophoretic behaviour typical of the ECHO viruses is illustrated by the Z.E. diagram of ECHO 3, Text-fig. 8 (a). Those which differ from the other members of the group examined are ECHO 7 and ECHO 8. Generally the viruses of this 
group show broad zones rather than well-defined peaks of activity. This makes it difficult to determine virus mobility relative to that of haemoglobin and phenol red. In most of the ECHO types investigated the peaks of activity of the virus do not coincide exactly with a major zone of light scattering, e.g. that of ECHO 4,

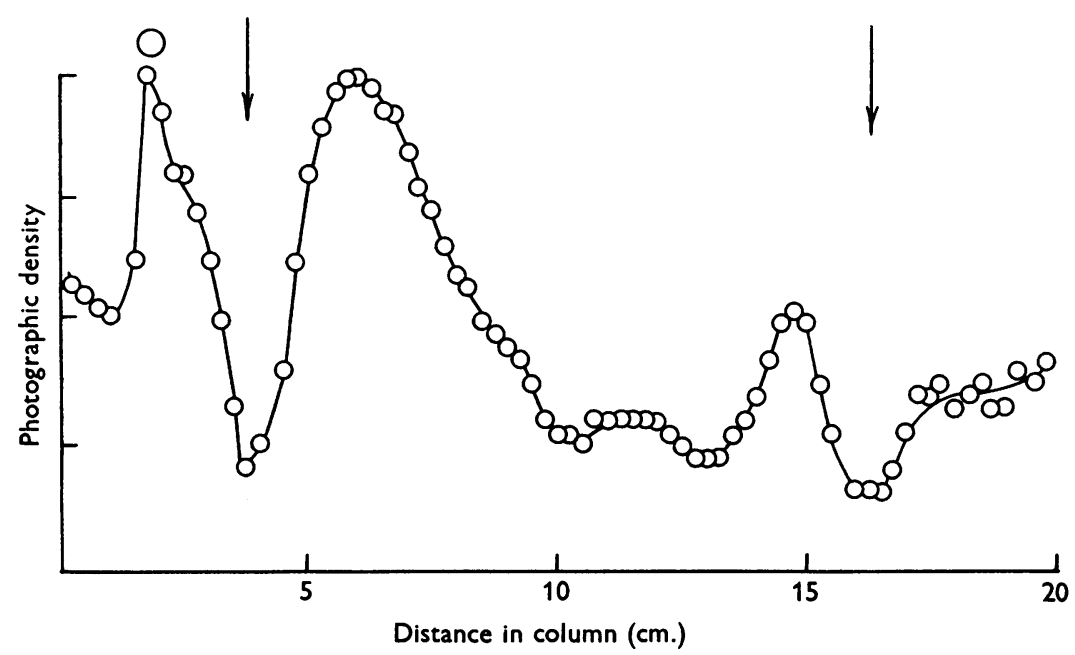

Text-fig. 5. Light-scattering diagram obtained from Z.E. run on Coxsackie A4 virus concentrate (suckling mouse material). See Text-fig. 3 for the significance of ' $O$ ' and the arrows. The virus peak titre was found immediately to the left of haemoglobin zone (the arrow on the left in the figure).

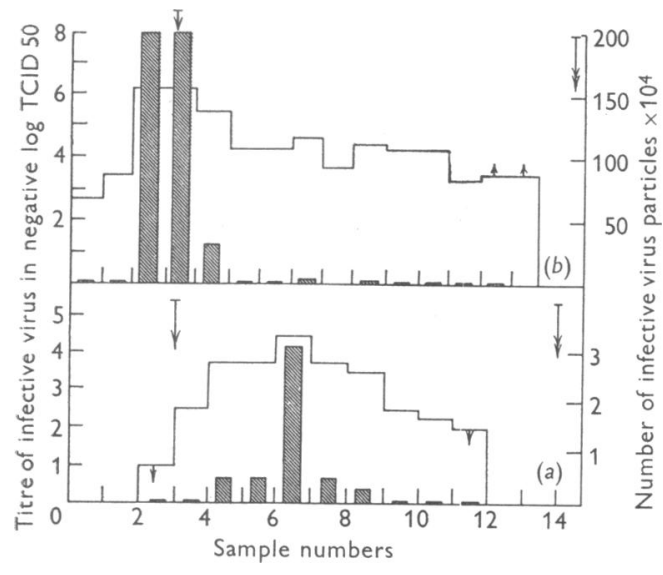

Fig. 6

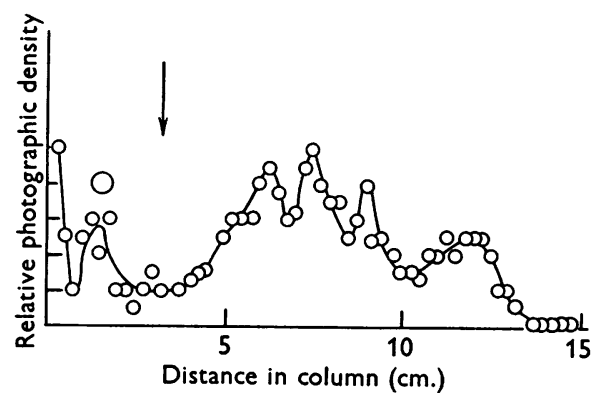

Fig. 7

Text-fig. 6. (a) Zone electrophoresis histogram of Coxsackie B 1, a typical member of this group of viruses. (b) Histogram of Coxsackie B 3 whose electrophoretic behaviour differs from that of the remaining Bs. Tissue culture material was used in both (a) and (b).

Text-fig. 7. Light-scattering diagram obtained from photograph of column after Z.E. of Coxsackie B 1 virus. See Text-fig. 3 for the significance of the arrows and ' $O$ '. The peak activity coincides in this case with the main light-scattering region. Compare with Fig. $6(a)$. 


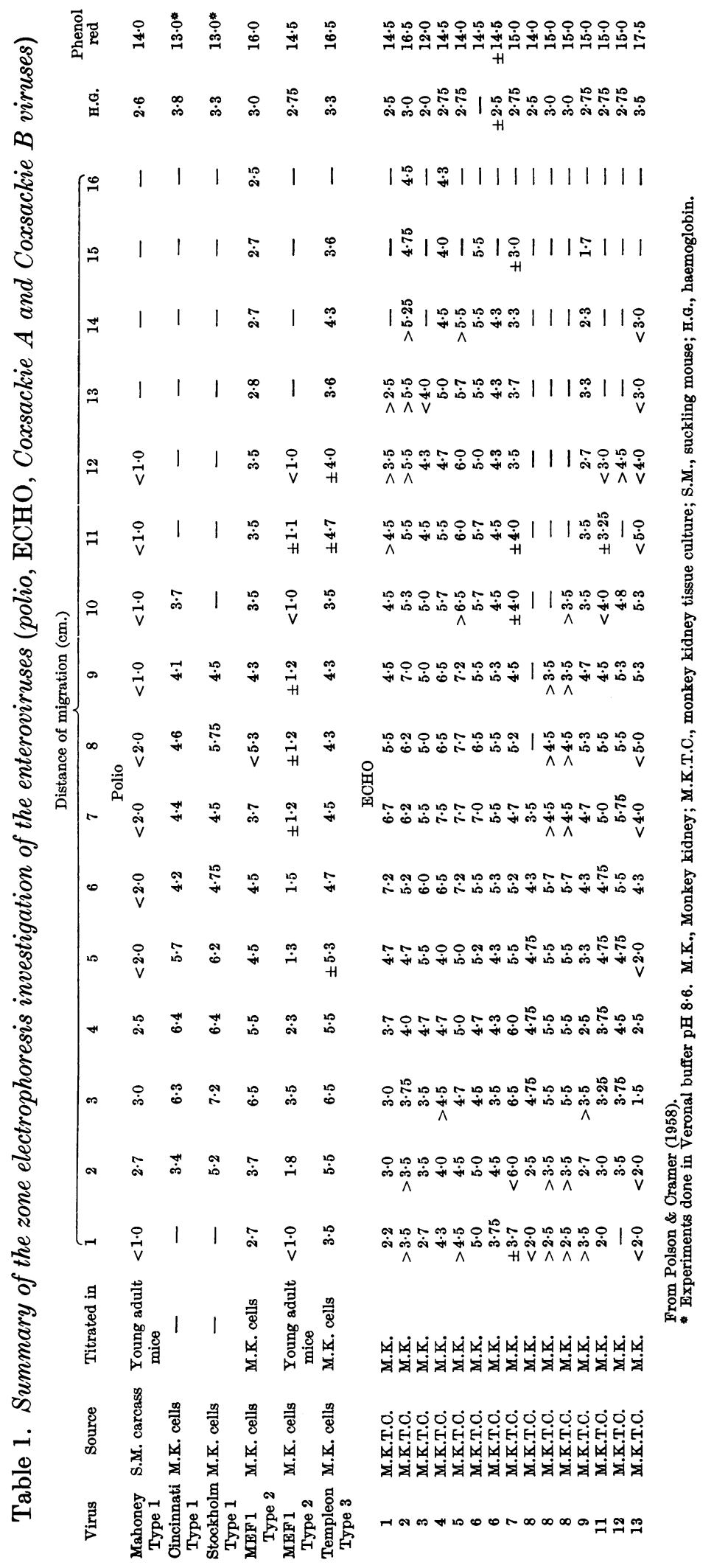




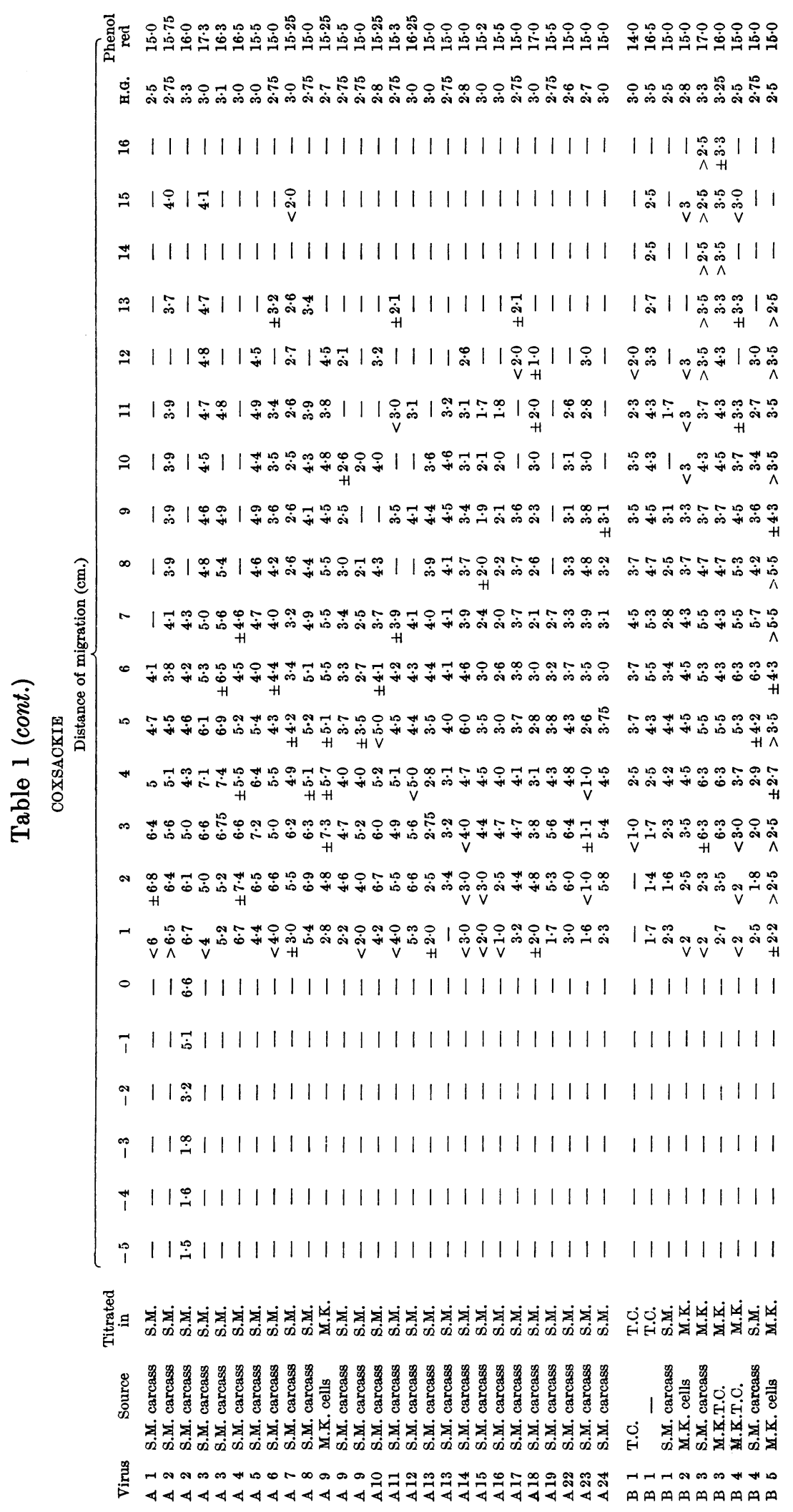


Text-fig. 9. The bulk of the virus may thus be separated from extraneous material upon prolonged zone electrophoresis.

In Table 1 a summary of the results of the Z.E. investigation of the enteroviruses is presented. Most of the members of these groups are represented; of the ECHO group, twelve members have been investigated.

\section{Electrophoretic inhomogeneity}

Several of the diagrams suggested the presence of an additional faster-migrating, minor zone of infectivity, or apparent electrophoretic inhomogeneity. As the minor peaks were the last to be collected from the column during the sampling process,

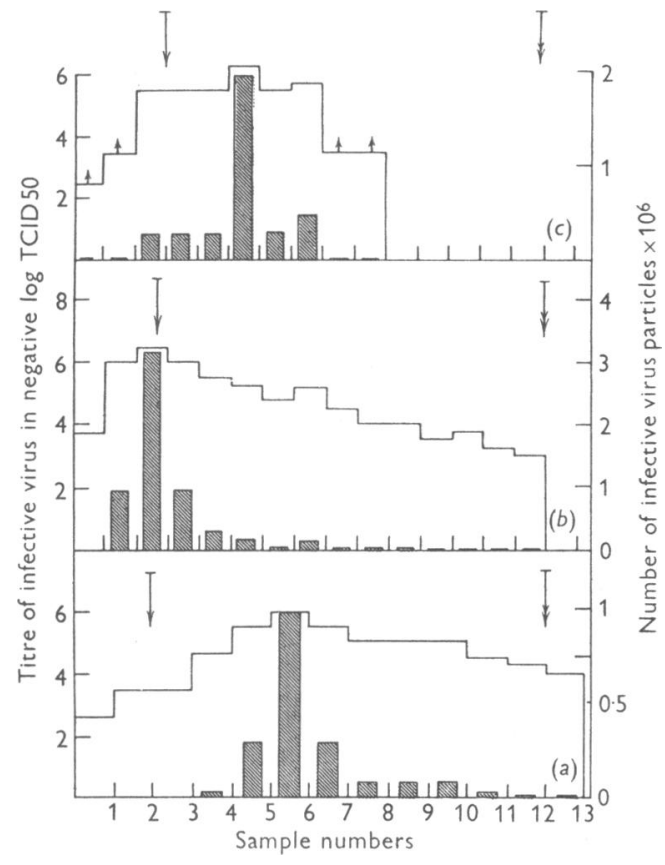

Fig. 8

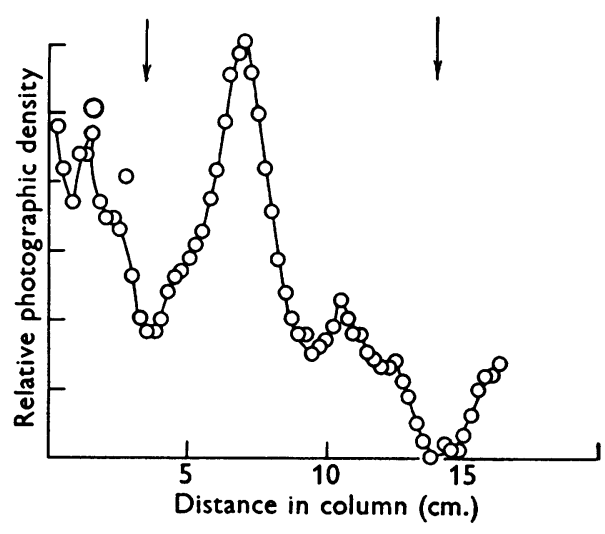

Fig. 9

Text-fig. $8(a)-(c)$. Zone electrophoresis histograms of ECHO 3, 7 and 8 respectively (tissue culture material). The ECHO 3 result is typical. ECHO 7 gives a result similar to that of poliovirus and Coxsackie $A$ viruses.

Text-fig. 9. Light-scattering diagram obtained from photograph of column after Z.E. of ECHO 4 (tissue culture material). See Text-fig. 3 for the significance of ' $O$ ' and the arrows. The main zone of light scattering lies in the peak infectivity region.

contamination through lagging of the virus from previous samples in the column or capillary was suspected. Experiments were done to exclude the possibility of these minor peaks being artifacts.

Normally the virus concentrate is introduced through the capillary tube into the lower, dense region of the sucrose gradient, where it forms a layer at the $40 \%$ sucrose level (' $B$ ', or the bottom of the effective column on the histograms). Sampling is carried out through the same capillary. 
For the purpose mentioned above, however, Z.E. conditions were reversed. The virus concentrate (contained in a suitable sucrose concentration) did not come in contact with the capillary tube at any stage, but was carefully introduced at the top, less dense region of the sucrose gradient (' $T$ ' on the histograms) by means of a pipette. Migration was then caused to proceed downwards. Sampling was later carried out as usual through the capillary tube at the bottom of the column.

The diagrams are presented in the usual manner, no matter which method was used. Distance of migration was naturally always measured from the origin, i.e. from the bottom upwards in normal runs, and from the top downwards in 'descending' runs-the only differences being the starting position, and the direction of migration. The first sample collected from a normal run is thus 'sample 1', and from a 'descending' run 'sample 15' or the appropriate number representing the distance of migration of the phenol red from the origin.

If a definite entity of high mobility does exist, it will, under these reversed conditions, be collected from the column before the major component, thus avoiding any contamination through 'tailing' of virus. Furthermore, if the two components can be separated, again subjected to electrophoresis separately and are then found to behave as single components, the original mixture must have contained the two components. Finally, if the original virus suspension is composed of two different viruses, it should be possible to separate them by Z.E. and to propagate them separately. Such virus cultures should then behave as single entities on subsequent electrophoresis. Coxsackie B 3 was selected for study along these lines.

The results of two separate experiments in which the virus was allowed to migrate down a sugar gradient column appear in Text-fig. $10(a)$ and (b). Although the Z.E. diagrams obtained are not identical with those presented in Text-fig 10 (c) and $(d)$ which were obtained by the normal ascending technique, they do show the presence of the two components. The object of the two experiments $(c)$ and $(d)$ was to show the degree of reproducibility of the results.

The prominence of the faster-migrating peaks in the descending Z.E. diagrams may be accounted for by the compression of the zone as it moves into the increasing sugar concentration. The ascending and descending Z.E. techniques produce differences in conductivity gradients and electrolyte distribution after zone electrophoresis (Svensson, 1960), but these disparities influence only the distance of migration and the degree of separation of the components as evidenced by the new positions of the haemoglobin and the phenol red.

The samples from the two peak activity regions were again subjected, separately, to zone electrophoresis in the normal way (Text-fig. $11(c)$ and $(d)$ ). Text-fig. $11(b)$ is a copy of the original descending Z.E. diagram from which the two diagrams $11(c)$ and $(d)$ were derived, and Text-fig. $11(a)$ is a normal ascending Z.E. diagram for the purpose of comparison.

Text-fig. $11(c)$ shows that the slow fraction retained its mobility on re-electrophoresis, giving a picture similar to that of a normal ascending Z.E. run. Textfig. $11(d)$ is a diagram of the fast-moving fraction showing that both components are still present, probably due to inadequate initial separation, the highest peak of 


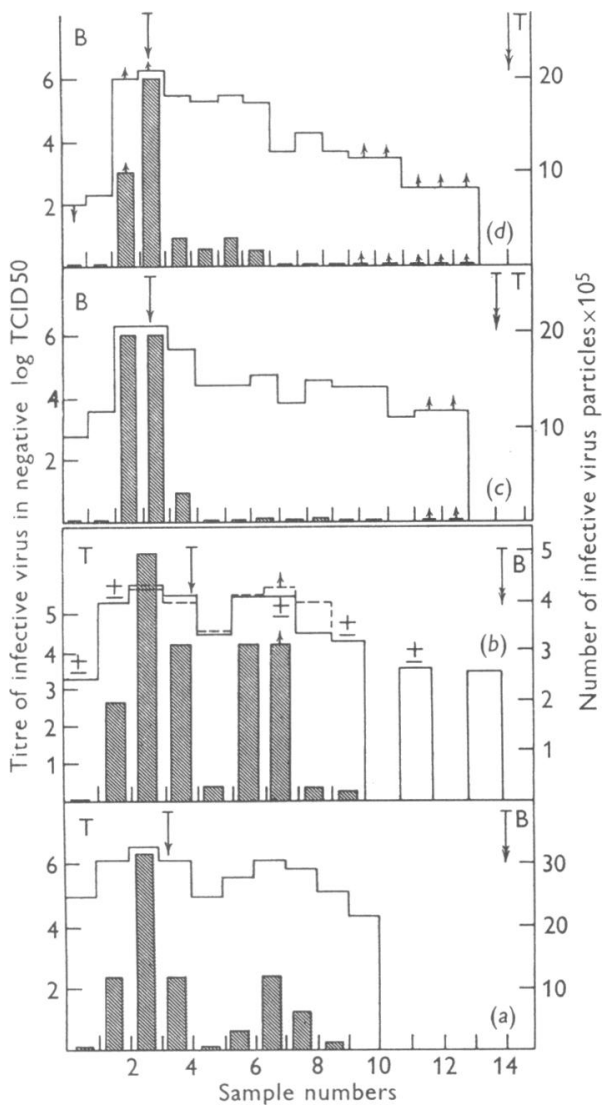

Fig. 10

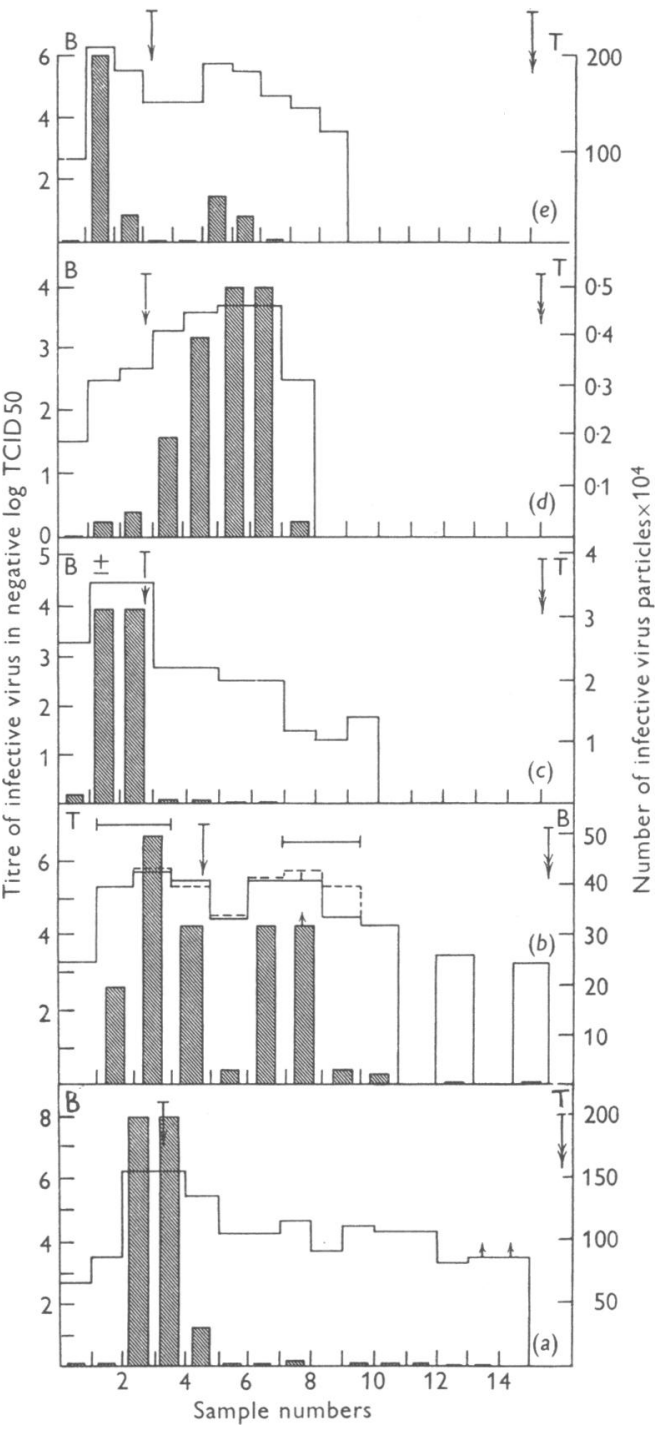

Fig. 11

Text-fig. 10. Zone electrophoresis histograms of Coxsackie B 3 virus. In all diagrams $T$ indicates the top and $B$ the bottom of the sucrose gradient.

(a) 'Descending' technique (tissue culture material). Five tubes per tenfold dilution were used in this titration. (b) 'Descending' technique (tissue culture material). The titrations of samples 3 to 8 were repeated (see broken lines on unshaded histogram). (c) 'Ascending' or normal technique (tissue culture material). (d) 'Ascending', normal technique (suckling mouse carcass material).

Text-fig. 11. (a) 'Ascending' (normal) technique Z.E. diagram of Coxsackie B 3 virus. (b) 'Descending' technique Z.E. diagram of Coxsackie B 3 from which the slow(samples 2 and 3) and fast-migrating fraction (samples 7 and 8 ) were isolated. The zones from which the two fractions were taken are indicated by horizontal lines. $\mathrm{T}$ indicates the top and $\mathrm{B}$ the bottom of the sucrose gradient. $(c),(d)$ Zone electrophoresis histograms of the respective slow and fast components derived from $(b)$. Normal Z.E. technique used. (e) Zone electrophoresis histogram of the subcultured fast component. Normal Z.E. technique used. Tissue culture material was used in these runs. 
activity being present in the position of the 'fast' component, i.e. it has retained its mobility.

To establish whether the two electrophoretically separable components were different viruses or fractions of the same virus carrying different electrical charges, subcultures were made from the highest infective dilution of the faster-migrating component. Text-fig. $11(e)$ clearly indicates that both components are present on subculture of the faster-migrating fraction.

Text-figs. 12 and 13 are Z.E. diagrams which indicate the degree of reproducibility of the results. The Coxsackie A 13 virus was derived from suckling mouse carcasses and titrated in suckling mice (Text-fig. 12). The experiments on Coxsackie B 4 were done on both suckling mouse and M.K. tissue culture material and titrated in suckling mice and M.K. cells, respectively (Text-fig. 13).

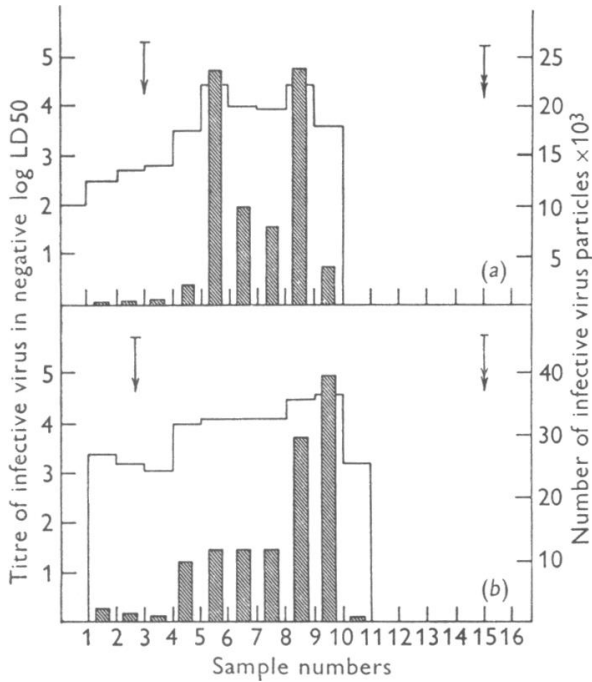

Fig. 12

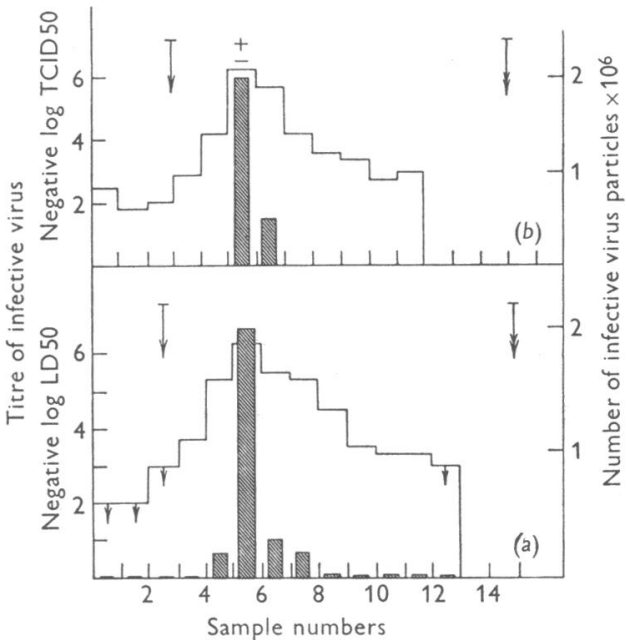

Fig. 13

Text-fig. 12. Zone electrophoresis diagrams of Coxsackie A 13 virus. Two separate experiments are presented. Suckling mouse carcass material was used.

Text-fig. 13. (a) Zone electrophoresis diagram of Coxsackie B 4 virus derived from and titrated in suckling mice. (b) Zone electrophoresis diagram of Coxsackie B4 virus derived from and titrated in M.K. cells.

\section{Virus purification for the production of specific immune sera}

Zone electrophoresis is admirably suited for purification of the majority of the enteroviruses prior to the production of specific precipitating antibodies. In order to illustrate the suitability of the method Coxsackie A3 virus was grown in suckling mice and partially purified by ultracentrifugation and chloroform treatment. The virus was further purified by zone electrophoresis. The fraction with the highest infective titre was concentrated by ultracentrifugation and injected subcutaneously into six guinea-pigs. Each animal received six inoculations at intervals of 3 days and was bled by heart puncture 14 days after receiving the last injection. Micro-Ouchterlony tests were carried out on the purified antigen 
and the immune sera (Pl. 2, fig. 2). In all the sera tested only one line of precipitation was visible. In control tests using crude saline extracts of normal and infected suckling mouse carcasses only the infected material showed a faint line of precipitate which was close to the antigen well.

\section{Electron microscopy}

The virus preparation may be subjected, finally, to electron microscopy in order to demonstrate the degree of purification that has been achieved. Pl. 2, figs. $3 a, b$, shows electron micrographs of Coxsackie B 3 and ECHO 1 viruses, respectively, purified by zone electrophoresis. The ECHO preparation appears to be completely free of extraneous material, but the Coxsackie B 3 suspension appears to have some foreign material associated with the virus particles.

\section{The influence of the host cell on the electrophoretic mobility}

A few suitable enteroviruses were propagated in both M.K. cells and in suckling mice.

Text-fig. $13(a)$ and $(b)$ shows the results obtained from two such Z.E. runs done on Coxsackie B 4 virus. There is no apparent difference between the diagrams.

Text-fig. $10(c)$ and $(d)$ of Coxsackie B 3 may be referred to as further examples of a virus obtained from different sources. The titrations of both $(c)$ and $(d)$, however, were done in M.K. cells. The diagrams are very similar.

ECHO 9 and Coxsackie A23, these being regarded here as the same virus (Sickles, Mutterer \& Plager 1959), show no difference in their electrophoretic behaviour, although the former was propagated in M.K. cells and the latter in suckling mouse carcass. The diagrams are not presented here, but the results may be found in Table 1. It is interesting to note that though two end points were missed in the ECHO 9 titration, the broad peak is in the typical 'ECHO position', and that Coxsackie A 23 gives a similar result. Only one run was done on each virus.

In the case of Coxsackie B 1, again cultured in M.K. cells and in suckling mouse carcass, there is little evidence of any difference (see Table 1). This applies to Coxsackie A 9. There is, however, the suggestion that relatively more of the fastermigrating, low-titre component is present in the material derived from M.K. cells than in that obtained from suckling mouse carcass (see Table 1). There was a delay of 10 days and 3 weeks before the titration of the samples in the latter case. This may be significant.

\section{DISCUSSION}

It is proposed in this work that a physical characteristic be used in addition to biological properties for classifying the enteroviruses. To this end the mobility rate of the infectious agent under standardized experimental conditions in zone electrophoresis seems to be admirably suitable. It was found that the main components of the poliovirus group had the same mobility in the electric field and that the greater majority of the Coxsackie A members showed a migration rate indistinguishable from that of the poliovirus group. Of the twenty individuals investigated in this group three were found to behave differently. These were Coxsackie A 2, which 
showed zero mobility under the standardized conditions, and A 13, A 14 and A 23, all of which had mobilities markedly higher than the rest of the members.

The Coxsackie B viruses as a group behaved differently from the polioviruses and Coxsackie $A$ viruses, since their main components migrate appreciably faster than those of the majority of the two preceding groups. Coxsackie B3 shows a main component which migrates at the same rate as the main constituents of the polioviruses and Coxsackie $A$ viruses and a minor fraction which behaves as the rest of the Coxsackie $B$ family. In further experiments with the $B 3$ viruses it was found that the two components are distinct, as they could be separated from each other by Z.E. and upon re-electrophoresis behaved as single entities. It was also found that the faster-migrating fraction of Coxsackie B 3 virus was not a different virus as both electrophoretically separable fractions were produced after subculture.

The majority of the ECHO viruses investigated in this work have electrophoretic mobilities which are slightly higher than those of the rest of the family of enteroviruses. Some ECHO viruses do not obey this rule. These are ECHO 7 which has the same mobility as the majority of the Coxsackie A group and ECHO 8 which in turn has the same mobility as Coxsackie A 13 virus.

In addition to the grouping of the enteroviruses according to their mobilities in the electric field, it was found that these infectious agents could be partially or completely freed from associated tissue debris by zone electrophoresis. This is evident from electron micrographs taken of Coxsackie B 3 and ECHO 1 viruses. It further became clear from an examination of the Tyndall light-scattering diagrams that there are several bands of tissue components which are separable from the viruses by zone electrophoresis. The ECHO and Coxsackie B viruses were partially separated from a band of opalescent material which migrates slightly faster than haemoglobin, and it may be estimated that approximately $90 \%$ of the activity of the majority of these two classes of enteroviruses may be recovered from the column in a relatively pure state. The polioviruses and Coxsackie A viruses may also be purified with relative ease, for their peaks of activity are not associated with bands of opalescent material on zone electrophoresis. The separation of the enteroviruses from associated tissue components is of importance as type-specific precipitating antibodies may now be prepared against these infectious agents which may be of great value in their identification. The practicableness of this procedure was demonstrated on the production of precipitating antibody against Coxsackie A 3 .

The type of infected tissue which acted as source of virus does not seem to influence the rate of migration of the infective agents in the electric field. It may possibly alter the ratio of the titres of the virus in the major and minor peaks.

An interesting finding was that Coxsackie A23 virus behaved like a typical ECHO virus in zone electrophoresis. Using this criterion it should be classed as an ECHO virus, more specifically as ECHO 9, and not as a Coxsackie A virus.

In conclusion it may be mentioned that the behaviour of the enteroviruses in the electric field may be predicted from their behaviour in adsorption and elution chromatography on cellulose ion exchangers. Thus the order in which polio and ECHO 9 viruses were eluted from ETEOLA cellulose ion exchanger (Hoyer, Bolton, Ormsbee, LeBouvier, Ritter \& Larson, 1958) was that of their mobilities in the 
electric field. In unpublished work from this laboratory (Kipps, Turner \& Polson) the order of elution of the viruses of lumpy skin disease from DEAE cellulose ion exchanger also paralleled their order of migration in the electric field.

\section{SUMMARY}

Zone electrophoresis in a sugar concentration gradient is proposed as a complementary method for the biological classification of the enteroviruses. Under standardized experimental conditions it was found that the majority of the Coxsackie A viruses and the polioviruses have a common, low electrophoretic mobility. The impression was gained that the ECHO viruses show the highest electrophoretic mobility, though in some cases there is overlapping with the Coxsackie Bs. The mobility of both of these groups is considerably higher than that of the other two.

Zone electrophoresis appears to be an excellent method for the purification of the enteroviruses prior to the production of specific precipitating antibodies.

The authors would like to thank Prof. Kipps for his continued interest and Dr Golda Selzer and Dr W. Bekker for their valuable co-operation in the earlier stages of this work.

\section{REFERENCES}

Cramer, R., Lerner, K. D. \& Polson, A. (1957). Sci. Tools, 4, 1.

ElfoRd, W. J. (1938). In Doerr-Hallauer, Handbuch der Virusforschung. 1 Hälfte, Wien.

Hoyer, B. H., Bolton, E. T., Ormsbee, R. A., LeBouvier, G., Ritter, O. B. \& Larson, C. L. (1958). Science, $127,859$.

Polson, A. \& Cramer, R. (1958). Biochim. Biophys. Acta, 29, 187.

Polson, A. \& Hampton, J. W. F. (1957). J. Hyg., Camb., 55, 344.

Polson, A., Hampton, J. W. F. \& Deeks, D. (1960). J. Hyg., Camb., 58, 419.

Polson, A. \& Selzer, G. (1954). Biochim. Biophys. Acta, $14,67$.

Polson, A., Selzer, G. \& van den Ende, M. (1957). Biochim. Biophys. Acta, 24, 600.

Regenmortel, Van, M. H. V. (1960). Virology, 12, 127.

Sickles, G. M., Mutterer, M. \& Plager, H. (1959). Proc. Soc. exp. Biol., N.Y., 102, 742. Svensson, H. (1960). Lab. Manual Anal. Meth. Protein Chem. Vol. 1.

Svensson, H. \& Valmet, E. (1955). Sci. Tools, 2, 11.

\section{EXPLANATION OF PLATES}

\section{Plate 1}

Fig. 1. Zone electrophoresis apparatus, right, and fluorescent lamp for illuminating the column, left. The ground glass joints facilitate cleaning of the apparatus. The gradient is formed in the long, central vertical column. The electrode vessels can be seen in the background. The capillary tube through which the original material is introduced and from which the samples are collected after Z.E. is seen just above the level of the U-bend in the main column. Its outlet is directly below at the screw clamp and rubber tubing. Forty per cent sucrose is introduced through the bent capillary tube to the right.

\section{Plate 2}

Fig. 2. Micro-Ouchterlony tests on samples obtained from a Z.E. experiment on Coxsackie A 3. The numbers refer to the positions of the samples in the column. Sera from three immunized guinea pigs were tested separately. Single lines of precipitate were formed at samples 3,4 and 5 , indicating a maximum antigenic content at sample 4.

Fig. 3. (a) Electron micrograph of Coxsackie B 3 virus purified by zone electrophoresis. (Tissue culture material.) The large white sphere is a polystyrene latex particle (diameter $138 \mathrm{~m} \mu$ ). (b) Electron micrograph of ECHO 1 virus after zone electrophoresis. (Tissue culture material.) The diameter of the polystyrene latex particle is $138 \mathrm{~m} \mu$. 


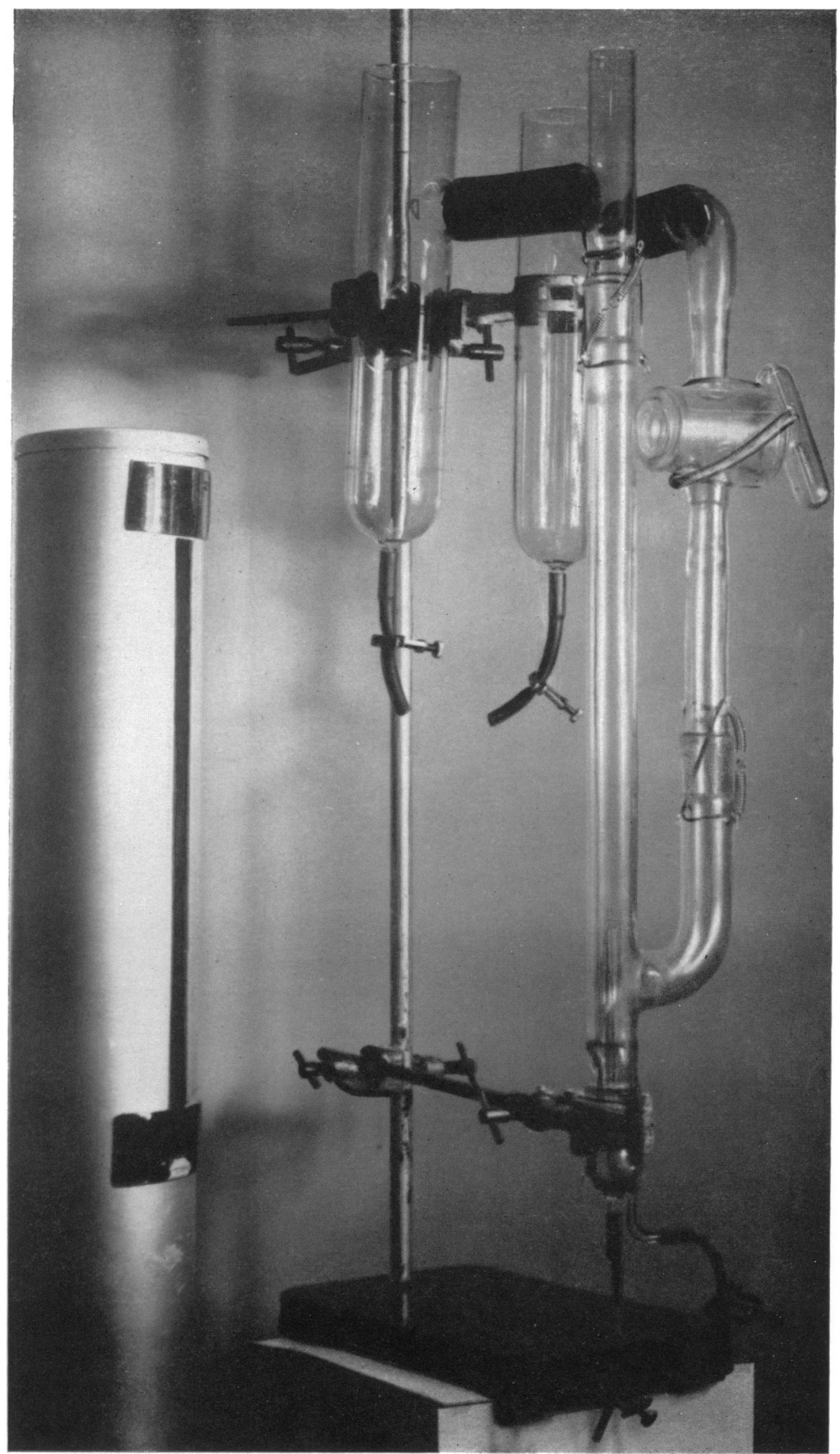



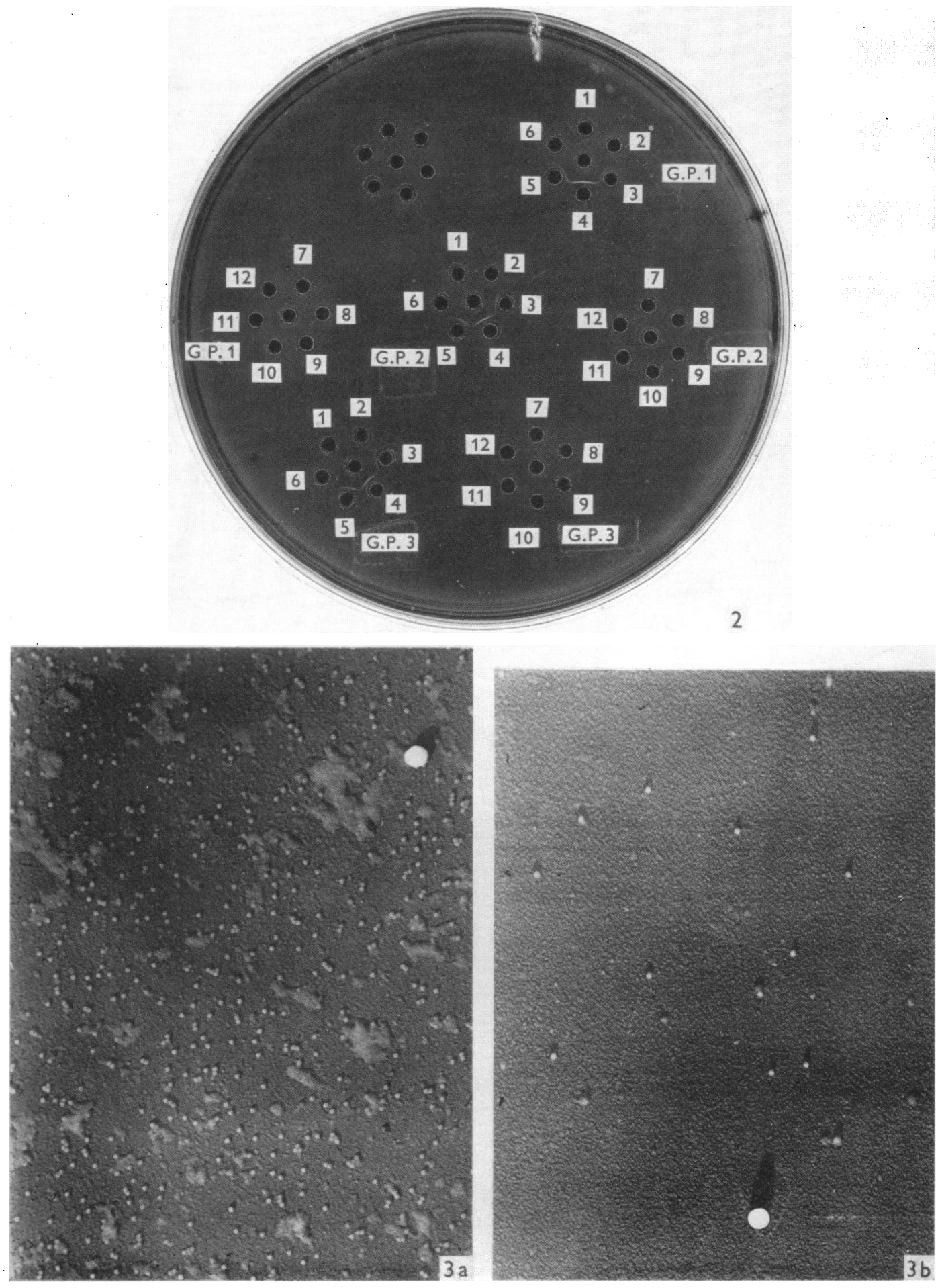

A. POLSON ANd D. DEEKS 